\title{
Envolvimento paterno no período gravídico-puerperal: revisão integrativa da literatura
}

\section{Paternal involvement in the pregnancy-puerperal period: an integrative literature review}

Cilas Viana de Freitas ${ }^{1}$, Yago Rodrigues Silva ${ }^{2}$, Marcelino Maia Bessa ${ }^{3}$, Rodrigo Jácob Moreira de Freitas ${ }^{4}$, Maura Vanessa Silva Sobreira ${ }^{5}$

1. ORCID: https://orcid.org/0000-0003-4516-7456. Especialização. Enfermeiro assistencial na Unidade Saúde da Família Caetano Bezerra do Nascimento, Pau dos Ferros, Rio Grande do Norte, Brasil. E-mail: cilasviana@hotmail.com.

2. ORCID: https://orcid.org/0000-0003-3759-7253. Especialização. Enfermeiro assistencial no Hospital Universitário Alcides Carneiro, Campina Grande, Paraíba, Brasil. E-mail: yago_ rz@hotmail.com.

3. ORCID: Ensino Superior - Incompleto. Graduando em Enfermagem pela Universidade do estado do Rio Grande do Norte, Pau dos Ferros, Rio Grande do Norte, Brasil. E-mail: marcelino.maia.18@outlook.com.

4. ORCID: https://orcid.org/0000-0002-5528-2995. Doutorado. Docente Adjunto II do curso de Enfermagem da Universidade do Estado do Rio Grande do Norte. Pau dos Ferros, Rio Grande do Norte, Brasil. E-mail: rodrigojmf@gmail.com.

5. ORCID: https://orcid.org/0000-0001-6804-4198. Doutorado. Professora Adjunta IV do Departamento de Enfermagem da Universidade do Estado do Rio Grande do Norte, Caicó, Rio Grande do Norte, Brasil. E-mail: mauravsobreira2@gmail.com.

CONTATO: Nome do autor correspondente: Marcelino Maia Bessa | Endereço: Sítio Encanto de Cima, Zona rural, Encanto-RN, Brasil. Telefone: (84) 9813472-7234 - E-mail: marcelino.maia.18@outlook.com 
RESUMO Este estudo tem como objetivo revisar a literatura científica relativa à participação do homem/pai brasileiro durante o período gravídico/puerperal. Foi realizado consulta nas bases LILACS, BDENF e na biblioteca SciELO, norteado pela questão: como se dá a participação do homem/pai durante o período gravídico puerperal no Brasil? Foram utilizados 12 artigos publicados entre os anos 2004 a 2019. Como resultados emergiram quatro categorias centrais: envolvimento paterno, sentir-se pai, conformação do modelo paterno nos dias atuais e relação paterna com os serviços de saúde durante a gestação e parto, as quais foram analisadas e discutidas sob a ótica da literatura consultada. Dentre outros achados, o presente estudo demonstra o quão complexo é conformação paterna no ciclo gestatório e sua tendência natural de distanciar-se do processo, contribuindo consequentemente para fragilização dos vínculos formados entre pai e filho e para dificuldade do desenvolvimento de práticas de cuidado.

DESCRITORES: Paternidade. Gravidez. Período Pós-Parto.

ABSTRACT This study aims to review the scientific literature on the Brazilian man/father participation during the pregnancy / puerperal period. The LILACS, BDENF and SciELO library databases were consulted, guided by the question: how does the man / father participation take place during the puerperal pregnancy period in Brazil? Thirteen articles published between the years 2004 to 2019 were used. As a result, four central categories emerged paternal involvement, feeling like a father, shaping the paternal model nowadays and paternal relationship with health services during pregnancy and childbirth, which were analyzed and discussed from the consulted literature perspective. Among other findings, the present study demonstrates how complex the father's resignation is in the gestational cycle and his natural tendency to distance himself from the process, consequently contributing to the weakening of the bonds formed between father and son and to the difficulty in the development of care practices.

DESCRIPTORS: Paternity. Pregnancy. Postpartum Period. 


\section{INTRODUÇÃO}

1 gestação configura um período de transformação na vida do casal, no qual se observa que os papéis e hábitos exercidos pelo homem e pela mulher, na vida a dois, sofrem alteração em virtude da expectativa da chegada de um novo ente familiar. Nesse sentido, a formação da paternidade e da maternidade constitui uma situação conflituosa na vida do casal' ${ }^{1}$.

Durante a gravidez, homens e mulheres passam a assumir novos papéis no contexto familiar, deixando a posição de filho ou filha e assumindo a postura de pais. Tal transição e as incertezas quanto ao curso e desfecho da gestação resultam em sentimentos de alegria, tristeza, satisfação e ansiedade, o que pode ser resolvido de forma harmoniosa ou não, a depender do casal².

Nesse contexto, apesar da gestação desenvolver-se no corpo feminino, o homem também sofre as expectativas da gravidez. O peso da responsabilidade sobre o feto que se desenvolve no ventre materno, alterações comportamentais e biológicas que nem sempre são compreendidas e a preocupação de suprir as necessidades familiares levam o homem a vivenciar um período conflituoso ${ }^{3}$.

Somam-se a isso, as alterações que o conceito de paternidade vem sofrendo ao longo da história. No que tange a isso, o homem vive uma situação dicotômica entre uma configuração familiar patriarcal, na qual o papel de pai limita-se a prover o sustento familiar, e um cenário no qual se torna gradativamente mais presente no âmbito doméstico/ familiar, mais afetuoso e participativo na criação dos filhos ${ }^{1}$.

Nessa perspectiva, os pais se encontram em um conflito interno quanto ao seu papel fundamental na esfera familiar, entre se tornar um pai mais tradicional, conceito esse que ainda é bastante presente no ambiente intrafamiliar contemporâneo, ou vivenciar uma experiência ainda recente, que é a de ser mais envolvido e participativo nas relações familiares ${ }^{2}$.

Além disso, a falta de espaços para participação paterna durante o período gestacional nos serviços de saúde, desde o pré-natal até o parto contribui para intensificar o distanciamento do homem neste processo. Nesse sentido, há necessidade de construir medidas específicas para atender tal necessidade, a fim de minimizar os conflitos existentes nessa população e aproximar o homem de sua companheira ${ }^{4}$.

Dessa forma, a percepção paterna quanto ao processo gestatório deve ser estudada, tendo em vista a complexidade de relações que se formam durante esse período, além de buscar-se maior participação do homem nessa fase de desenvolvimento do casal, uma vez que essa relação de proximidade apresenta impactos no desenvolvimento gestacional e no bem-estar da mulher e da criança após o nascimento, seja de forma 
positiva pela sua presença, participação e aceitação, seja de forma negativa por sua ausência, resistência ou negação da gravidez 5 .

Diante do exposto, o presente artigo tem como objetivo revisar a literatura científica relativa à participação do homem/pai brasileiro durante o período gravídico/puerperal.

\section{MÉTODO}

Trata-se de uma revisão integrativa da literatura, definida como um método de revisão específico que visa a fornecer uma visão abrangente sobre determinado tema e que tenha utilidade para a prática. O percurso metodológico seguiu as seguintes etapas: formulação do problema, coleta dos dados, avaliação dos dados coletados, análise e interpretação dos mesmos e apresentação dos resultados ${ }^{6}$.

Inicialmente, para direcionar esta revisão, foi elaborada a seguinte questão norteadora: "Como se dá a participação do homem/pai durante o período gravídico puerperal no Brasil?". O levantamento foi realizado pela internet, através das seguintes bases de dados: Literatura Latino-Americana e do Caribe em Ciências da Saúde (LILACS), Base de Dados de Enfermagem (BDENF) e na biblioteca Scientific Electronic Library Online (SciELO). Como estratégia de busca, utilizou-se dos Descritores em Ciências da Saúde (DeCS), através do seguinte operador de busca: Paternidade AND Gestação AND Pai.

Os critérios de inclusão foram: Artigos completos disponíveis gratuitamente on-line; Artigos disponíveis no idioma Português; Artigos que abordassem a temática proposta. Os critérios de exclusão dos estudos foram: Monografias, Editoriais; Cartas ao editor; Artigos em outros idiomas; Artigos que não abordassem a temática relevante ao alcance do objetivo da revisão integrativa.

A busca foi realizada pelo acesso on-line, utilizando os descritores em português, e os critérios de inclusão e exclusão. Inicialmente na busca dos descritores associados, foram encontrados no LILACS 47 artigos, no BDENF 18 e SciELO 12. Após o atendimento aos critérios de inclusão e exclusão, a amostra foi constituída de 12 artigos.

As estratégias de busca utilizadas nas respectivas bases de dados e os motivos da exclusão foram apresentadas na Figura 1, como recomendado pelo grupo PRISMA 7 .

Por tratar-se de pesquisa com enfoque em revisão da literatura, cujo propósito foi a análise secundária de dados, não envolvendo, portanto, seres humanos, não houve necessidade de apreciação e/ou aprovação por Comitê de Ética em Pesquisa (CEP). Além disso, cabe salientar que foi mantida a autenticidade das ideias, conceito e definições dos autores dos artigos. 
Figura 1. Fluxograma para seleção dos estudos encontrados.

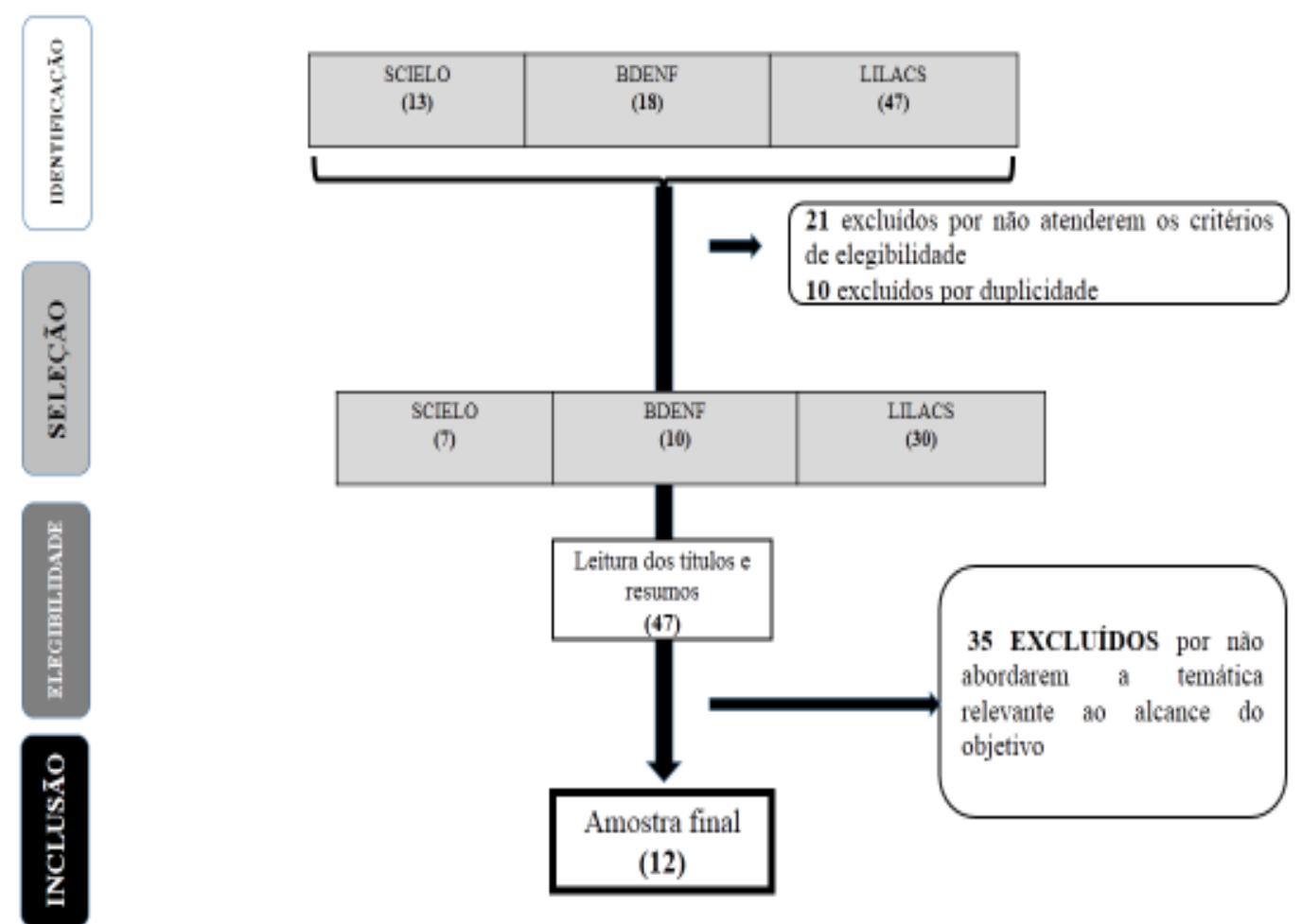

Fonte: elaborado pelos autores (2020)

\section{RESULTADOS}

A caracterização dos 12 artigos selecionados apresenta-se a Quadro 1, que apresenta a relação de artigos encontrados, por autoria, revista e ano, além dos principais achados dos artigos, no intuito de facilitar a apreensão dos resultados encontrados.

Quadro 1. Relação de artigos encontrados por autoria, revista, ano e principais achados.

\begin{tabular}{|l|l|}
\hline $\begin{array}{l}\text { Artigos/ } \\
\text { Revista/ano }\end{array}$ & \multicolumn{1}{|c|}{ Achados } \\
\hline $\begin{array}{l}\text { Bencke e Kruel }{ }^{3} \\
\text { Revistade } \\
\text { Psicologia }\end{array}$ & $\begin{array}{l}\text { Sentimento de paternidade somente após o nascimento; } \\
\text { Distanciamento do binômio mãe-filho pela impossibilidade do contato } \\
\text { direto com o feto; } \\
\text { Transição do modelo de paternidade; } \\
\text { Influências do modelo de paternidade vivenciado no papel paterno } \\
\text { exercido; } \\
\text { Alterações nas práticas sexuais durante e após período gestacional. }\end{array}$ \\
\hline $\begin{array}{l}\text { Cavalcanti e } \\
\text { Holanda }\end{array}$ & $\begin{array}{l}\text { Envolvimento paterno durante o ciclo gravídico-puerperal favorece } \\
\text { Enfermagem em } \\
\text { foco }\end{array}$ \\
2019
\end{tabular}




\begin{tabular}{|c|c|}
\hline $\begin{array}{l}\text { Freitas, Coelho e } \\
\text { Silva }^{8} \\
\text { Caderno de } \\
\text { Saúde Pública } \\
2007\end{array}$ & $\begin{array}{l}\text { O fortalecimento dos laços afetivos entre pai e filho favorece o vínculo } \\
\text { entre ambos; } \\
\text { Participação do homem na gestação fortalece o sentimento de paternidade; } \\
\text { Significados sociais de paternidade; } \\
\text { Variações da concepção de paternidade conforme o desenvolvimento da } \\
\text { gestação; } \\
\text { Transição do modelo paterno; } \\
\text { Confronto entre expectativas e realidade após o nascimento da criança; } \\
\text { Influências da concepção de gênero na construção do modelo paterno; } \\
\text { Resquícios do modelo de paternidade tradicional; } \\
\text { Influências da criação do próprio pai na construção do seu modelo de } \\
\text { paternidade. }\end{array}$ \\
\hline $\begin{array}{l}\text { Krob, Piccinini e } \\
\text { Silva }^{9} \\
\text { Psicologia USP } \\
2009\end{array}$ & $\begin{array}{l}\text { Desenvolvimento paterno do bebê imaginário; } \\
\text { Alterações comportamentais no pai após o nascimento da criança; } \\
\text { Transição do modelo paterno; } \\
\text { Influência da vivência enquanto filhos no exercício da paternidade; } \\
\text { Contraste entre a expectativa da paternidade durante a gestação e as } \\
\text { vivências após nascimento da criança; } \\
\text { Contraste entre o pai ideal e o pai real; } \\
\text { Engajamento dos pais na criação dos filhos em atividades recreativas; } \\
\text { Insegurança dificultava o envolvimento paterno nos cuidados diários; } \\
\text { Envolvimento paterno nos cuidados à criança de forma espontânea; } \\
\text { Sentimentos paternos ambivalentes durante a gestação; } \\
\text { Sentimento paterno de exclusão durante a gestação. }\end{array}$ \\
\hline $\begin{array}{l}\text { Piccinini et } a /^{10} \text {. } \\
\text { Psicologia: } \\
\text { Reflexão e Crítica } \\
2004\end{array}$ & $\begin{array}{l}\text { Os pais mais próximos à gestação desempenham melhores cuidados ao } \\
\text { recém-nascido; } \\
\text { Aproximação paterna durante a gestação; } \\
\text { Participação paterna nos cuidados à saúde durante a gestação favorece } \\
\text { o envolvimento entre pai e filho; } \\
\text { Dificuldade paterna em sentir a gestação; } \\
\text { Transição do modelo paterno; } \\
\text { Pouca intenção de assistir ao parto; } \\
\text { Aproximação paterna da gestação de forma gradativa, quanto mais } \\
\text { próxima do fim, maior é a aproximação; } \\
\text { Maior parte das preocupações referidas pelos pais relacionou-se com a } \\
\text { saúde e bem-estar do bebê e da gestante. }\end{array}$ \\
\hline $\begin{array}{l}\text { Piccinini et a }{ }^{11} . \\
\text { Estudos de } \\
\text { Psicologia } \\
2009\end{array}$ & $\begin{array}{l}\text { Recursos diagnósticos influenciaram positivamente a diminuição da } \\
\text { ansiedade paterna durante a gestação; } \\
\text { Pais retraem-se dos cuidados à criança por medo de machucá-las; } \\
\text { Imaginar características das crianças auxilia na construção da identidade } \\
\text { do mesmo; } \\
\text { Pais que constroem uma imagem da criança possuem maior envolvimento } \\
\text { nos cuidados ao bebê e a companheira. }\end{array}$ \\
\hline
\end{tabular}




\begin{tabular}{|c|c|}
\hline $\begin{array}{l}\text { Matos et a/12 } \\
\text { Psicologia USF } \\
2017\end{array}$ & $\begin{array}{l}\text { Sentimento de paternidade após o nascimento do filho; } \\
\text { Presença paterna precoce na gestação favorece a atenção aos cuidados } \\
\text { com o bebê; } \\
\text { Construção inicial do vínculo a partir do parto; } \\
\text { Distanciamento do ciclo gravídico-puerperal pelo sentimento de exclusão; } \\
\text { Mudança nas rotinas sociais. }\end{array}$ \\
\hline $\begin{array}{l}\text { Santos e } \\
\text { Antúnez }^{1} \\
\text { Arquivo brasileiro } \\
\text { de psicologia } \\
2018 \\
\end{array}$ & $\begin{array}{l}\text { Transição do modelo de paternidade; } \\
\text { Maior participação paterna durante o ciclo gravídico-puerperal; } \\
\text { Sentimento de paternidade após o nascimento do filho. }\end{array}$ \\
\hline $\begin{array}{l}\text { Soares et a/13 } \\
\text { Escola Anna } \\
\text { Nery Revista de } \\
\text { Enfermagem } \\
2015\end{array}$ & $\begin{array}{l}\text { Surgimento de novos papéis e tarefas após o nascimento do filho; } \\
\text { Preparação do ambiente para chegada do filho; } \\
\text { Influência cultural na conformação do modelo paterno; } \\
\text { Desenvolvimento do bebê imaginário; } \\
\text { Influência positiva do incentivo do profissional de saúde no ciclo gravídico- } \\
\text { puerperal favorece o vínculo entre pai e filho; } \\
\text { Pais apresentam dificuldade de interação durante a gestação; } \\
\text { Presença paterna no parto favorece o vínculo com a companheira e com } \\
\text { o filho; } \\
\text { Informações favorecem positivamente a relação pai e recém-nascido; } \\
\text { Transição do modelo de paternidade. }\end{array}$ \\
\hline $\begin{array}{l}\text { Sonego et } a^{2} \\
\text { Psicologia: Teoria } \\
\text { e Pesquisa } \\
2016\end{array}$ & $\begin{array}{l}\text { Sentimentos paternos ambivalentes na gestação; } \\
\text { Transição do modelo de paternidade; } \\
\text { Aproximação paterna durante a gestação favorece os cuidados com a } \\
\text { criança após nascimento; } \\
\text { Afastamento paterno do período gestacional; } \\
\text { Aproximação paterna da gestação de forma gradativa, quanto mais } \\
\text { próxima do fim, maior é a aproximação. }\end{array}$ \\
\hline $\begin{array}{l}\text { Trindade et al } \\
\text { Saúde e } \\
\text { sociedade } \\
2019\end{array}$ & $\begin{array}{l}\text { Distanciamento do processo gestacional; } \\
\text { Falta de acolhimento às demandas masculinas durante a gestação; } \\
\text { Mudança no modelo de paternidade; } \\
\text { Envolvimento paterno na gestação para prevenção do distanciamento } \\
\text { paterno após nascimento do bebê. }\end{array}$ \\
\hline $\begin{array}{l}\text { Castoldi, } \\
\text { Gonçalves e } \\
\text { Lopes }^{14} \\
\text { Psicologia em } \\
\text { estudo } \\
2014\end{array}$ & $\begin{array}{l}\text { A ausência de uma matriz de apoio e as percepções das mães sobre o } \\
\text { desempenho do marido como pai não pareceram influenciar diretamente } \\
\text { o nível de envolvimento com o bebê; } \\
\text { Continuam seguindo modelos tradicionais de paternidade; } \\
\text { Centra-se no papel de provedor financeiro; } \\
\text { Engajamento maior em atividades lúdicas do que nos cuidados do filho; } \\
\text { Influências intergeracionais e do discurso sobre o "novo pai" na prática da } \\
\text { paternidade. }\end{array}$ \\
\hline
\end{tabular}

Fonte: elaborado pelos autores (2020). 


\section{DISCUSSÃO}

Após leitura e releitura dos artigos encontrados, emergiram quatro categorias centrais, quais sejam, envolvimento paterno, sentir-se pai, conformação do modelo paterno nos dias atuais e relação paterna com os serviços de saúde durante a gestação e parto, as quais foram analisadas e discutidas, a seguir, sob a ótica da literatura consultada.

\section{Envolvimento paterno}

Os artigos demonstram uma realidade na qual o envolvimento paterno apresenta-se cada vez mais presente, sendo que tal relação se fortalecia conforme o desenvolvimento da criança ou mesmo do feto ${ }^{14}$.

Entretanto, o cuidado paterno sempre tendia a estar mais presente nas brincadeiras do que propriamente nos cuidados essenciais do bebê, tais como alimentar, banhar, trocar fraldas, etc. Essa característica foi motivada pela insegurança paterna ao realizar determinadas tarefas, pela falta de estímulo, pelo medo de machucar a criança ou pelo insucesso de tentativas anteriores ${ }^{9}$.

Quanto às tarefas relacionadas ao cuidado do bebê nota-se que os pais nem sempre as realizavam de forma espontânea, sendo necessário o estímulo para execução de tais tarefas e mesmo quando espontâneas elas possuíam caráter auxiliar, deixando a atividade principal sob responsabilidade materna. Tais aspectos justificaram-se pelo seu medo, insegurança, e pela crença de que as esposas tinham mais jeito do que eles, além do pouco tempo disponível para ficar junto ao bebê, preferindo, então, envolver-se em trocas afetivas ${ }^{9}$.

Soma-se a isso, a falta de tempo, resultante da extensa jornada de trabalho, e a preocupação com o sustento familiar que ainda apareceram como componentes que dificultam o estreitamento dos laços afetivos pai e filho ${ }^{9}$.

Vale destacar que a postura mais permissiva das mães durante o período gestacional pode facilitar a aproximação paterna desse processo. O que contribui positivamente não apenas para a maior participação do homem durante a gestação, mas também reforça os laços a serem construídos entre pai e filho posteriormente ${ }^{11}$.

Esse aspecto demonstra que os pais ainda tem dificuldade em envolver-se com a gestação, necessitando da iniciativa materna para consolidar a aproximação e que, apesar da transição de um comportamento paterno distante da criança e preocupado com o sustento familiar para um modelo mais presente e participativo, os resquícios do antigo modelo patriarcal ainda se encontram presentes no comportamento paterno ${ }^{14}$.

Faz-se necessário destacar a relevância dos primeiros meses após o nascimento do bebê, os quais são determinantes para o envolvimento paterno e para o desenvolvimento de práticas 
de cuidado, tanto do pai quanto da mãe. Nesse sentido, pode-se afirmar que esse período fomenta, ou não, o envolvimento paterno no cuidado ao filho em momentos posteriores².

Perspectiva essa que se contrapõe ao período gestacional, tendo em vista que, durante esse momento, o homem costuma distanciar-se da companheira por não se sentir parte do processo, pois a gravidez e o desenvolvimento fetal ocorrem no corpo materno. Nesse sentido, o homem tende a sentir-se desvalorizado o que dificulta o seu envolvimento com o binômio mãe-filho durante o período gestacional ${ }^{8}$.

Contribui ainda para esse distanciamento, o fato da dificuldade masculina de interagir com o binômio mãe-filho durante o período gestacional, especialmente com questões de ordem afetiva, fato que pode ser resultante tanto do processo cultural de formação masculina quanto de uma forma de defesa contra as angústias despertadas nesse período².

Diante disso, observa-se uma tendência de maior envolvimento paterno na gestação na medida em que ela se aproxima do nascimento, uma vez que a percepção das manifestações fetais funciona como um reforço positivo para o envolvimento dos pais. Nesse contexto, os pais começam a considerar o iminente nascimento do filho e iniciam o processo de personificação da criança, atribuindo-lhes características físicas e psicológicas e fortalecendo o envolvimento paterno com a mãe e com o filho².

Nesse cenário, evidencia-se a relevância advinda dos cuidados iniciais com o bebê para o estabelecimento do vínculo entre pai e filho, permitindo ao homem garantir seu lugar no grupo familiar e minimizando o sentimento de exclusão geralmente experimentado no período gestacional ${ }^{12}$.

Contudo, o medo e a preocupação dos pais em determinados casos podem funcionar como estímulos para a intensificação do cuidado com as gestantes, reforçando, assim, suas caraterísticas de protetor do lar, o que foi materializado por meio da organização da infraestrutura domiciliar, utensílios necessários ao cuidado e adaptação da rotina diária com a chegada do bebê².

Nesse sentido, os profissionais de saúde devem conhecer o complexo contexto psicossocial pelo qual passam os homens durante o período gestacional e proporcionarIhes informações e orientações necessárias ao cuidado e enfretamento das alterações ocorridas na gestação.

\section{Sentir-se pai}

O surgimento do sentimento de paternidade apresentou-se em diferentes momentos durante o ciclo gravídico-puerperal. Para alguns, esse sentimento já se iniciava ao saber da gravidez da companheira, para outros iniciou-se durante a percepção dos movimentos 
fetais na gestação, ainda houve casos em que a percepção da paternidade surgia ao nascimento da criança ou ainda posteriormente, durante a construção de laços afetivos no desenvolvimento da criança ${ }^{8}$.

Entretanto, esse é um universo complexo, permeado pelos diferentes conceitos quanto a significação da paternidade, pois para alguns pais, o simples conhecimento da gestação de sua parceira não traz à tona os sentimentos de paternidade, uma vez que esse momento marca a transição de representações do filho, saindo de um contexto imaginário e passando ao plano material. Esse cenário possibilita ao pai o contato direto com o filho, que até então só podia ser realizado indiretamente através da mãe, e, além disso, remete o pai às responsabilidades na criação de um filho. Dessa forma, o homem sente dificuldade em sentir-se pai durante a gestação, haja vista a posição predominantemente ideológica que a criança assume neste momento ${ }^{8}$.

Nesse sentido, considerar os componentes que determinam a construção da paternidade se fazem necessários para fortalecer os vínculos afetivos entre o binômio pai-filho, sejam eles formados na vida intrauterina ou mesmo fora do útero, já que isso favorece a melhoria no cuidado à saúde da criança.

Além disso, faz-se necessário considerar o âmbito cultural no qual o casal está inserido para compreender a forma como os papéis sociais de maternidade e paternidade foram construídos durante sua formação pessoal, pois tal processo influencia diretamente no modo como esses novos pais exercerão seus papeis. Dessa forma, o planejamento que os pais desenvolvem durante a gestação e os cuidados dispensados aos filhos após o nascimento dependem do processo cultural no qual esses indivíduos foram desenvolvidos ${ }^{13}$.

Nesse sentido, foi possível observar nos artigos que durante o período gestacional, os pais frequentemente idealizavam a figura paterna que queriam ser e relatavam aspectos que consideravam essenciais na construção da relação entre pai e filho tais como maior participação no cuidado dos filhos, oportunidade para transmitir princípios e valores que consideravam essenciais para formação social e o desejo de construir uma relação de amizade com seus filhos ${ }^{9}$.

Dessa forma, percebe-se que os pais reforçam aspectos da própria criação na forma de educar seus filhos, ao passarem por um processo que exige a revivência das relações com o próprio pai, com a mãe, consigo mesmo e sua história como filho, a partir do qual construirá e reconstruirá sua subjetividade na forma de exercer a paternidade ${ }^{3}$.

Contudo, apesar da notória preocupação em ser um pai presente na criação dos filhos, alguns resultados demonstraram que quando as mães apresentam-se ausentes, os pais tendem a ser mais participativos e acessíveis, corroborando o fato de que a priori o papel de cuidar é delegado à mãe, e num segundo momento, caso a mãe não esteja presente, esse papel é assumido pelo homem ${ }^{14}$. 


\section{Conformação do modelo paterno nos dias atuais}

Os estudos mostraram que a relação familiar vivida na atualidade tem modificado qualitativamente o significado da paternidade ${ }^{8}$.

Entretanto, o modelo de paternidade parece ainda estar em processo de redefinição, de modo que alguns pais desempenham seu papel de forma mais tradicional, enquanto outros apresentam uma postura mais ativa, com mais envolvimento e participação ${ }^{11}$.

Ficou evidente, em estudos ${ }^{11,14}$ a coexistência de identificações com modelos de paternidade modernas e tradicionais que dinamicamente se sobrepõem, conflitando ou convergindo, ao longo da transição para a paternidade, implicando, assim, diferentes trajetórias de envolvimento paterno.

Estudos sobre a transição para a paternidade, revelam que o confronto entre vivências intergeracionais da masculinidade tradicional, bem como as forças sociais e discursivas sobre o "novo pai" e a centralidade do trabalho para o homem produzem investimentos alternados em torno do modelo de paternidade mais próximo e afetuoso. Contudo, embora o desejo dos pais endossado pelas retóricas contemporâneas seja o de se aproximar desse ideal, repetidamente a prática da paternidade ainda tende a reproduzir papéis de gênero normativos ${ }^{10,14}$.

Culturalmente, a maternidade continua intimamente ligada ao cuidar e a manifestações afetivas para com os filhos. Assim sendo, a boa mãe é aquela que cuida, dá afago e alimenta. Por sua vez, a paternidade segue caminho oposto, sendo associada ao papel de provisão material, exortação, configurando o bom pai como aquele que não deixa faltar o alimento e dá lições para a vida aos filhos, sendo que esses comportamentos, frutos de estereótipos de gênero, desvalorizam a participação do homem na gravidez por reproduzir a máxima de que gestação é "coisa de mulher"8,13.

Nesse sentido, a dificuldade de o pai sentir a gravidez como experiência compartilhada pode ser relacionada com a reprodução ideológica da noção de homem/ pai e mulher/mãe, historicamente construída e culturalmente preservada, haja visto que mitos e símbolos culturais, presentes desde a antiguidade, direcionam os papéis sociais de gênero, excluindo, dessa maneira, o homem de uma participação mais efetiva neste processo ${ }^{8}$.

No tocante a isso, a literatura também nos remete aos significados sociais da paternidade, entre eles o cumprimento de um dever, ao certificar o homem como capaz de fecundar uma mulher e de se confirmar macho, reprodutor e viril, trazendo implícito o ser pai como espaço de reconhecimento de poder e honra ${ }^{8}$.

Verificou-se, ainda, que a formação do modelo de paternidade depende também da relação vivida entre pai e filho, no passado, influenciando o modo como o homem 
compreende e assume a sua masculinidade. Nessa lógica, para sua realização como pai, busca-se referências em seu próprio pai ${ }^{8-9,14}$.

Observou-se também, em vários trabalhos, o discurso de busca do "novo pai", que rompe o modelo tradicional de paternidade, desenvolvendo sentimentos afetivos e de vínculo que favorecem a construção do trinômio pai-mãe-filho. Esses sujeitos sociais afastam-se do modelo tradicional de homens ríspidos e distantes, ao compartilhar da experiência que é vivida no corpo da companheira ${ }^{8-11,13}$.

Com isso, o "novo pai" visita o pai tradicional, mas afasta-se dele, dotando a paternidade de sentido mais amplo, percebendo-a desde a gravidez, iniciando ainda nessa fase a construção de vínculos afetivos que se firmarão com o nascimento. Essa transição social e cultural da paternidade, verificada em alguns estudos, revela uma superação, ainda que timidamente, do modelo hegemônico tradicional ${ }^{8,13}$.

No estudo ${ }^{4}$, a identificação de falas e ações que sinalizam a disposição de alguns homens em seguir um modelo paterno diferente do tradicional indica que o momento é de transição e que os pais são pressionados e se pressionam a atender ora a demandas relativas ao modelo tradicional/hegemônico de homem/pai/marido, ora ao modelo do novo pai. Em ambos os casos, são encontrados pais que anseiam pelo desempenho da paternidade durante a gravidez e após o parto e, ao mesmo tempo, sentem-se inseguros com relação a seu desempenho.

Assim, é válido frisar que a questão da paternidade ultrapassa os limites da família e se torna um campo concreto de discussão no âmbito da saúde sexual e reprodutiva e da saúde coletiva ${ }^{8}$.

\section{Relação paterna com os serviços de saúde durante a gestação e parto}

Os estudos revelaram a necessidade de atendimento e acolhimento não apenas à mulher, durante o ciclo gestatório, mas também ao homem, garantindo aos dois a oportunidade de expressar sentimentos e vivencias, auxiliando-os na construção das novas identidades, as de pai e mãe ${ }^{13}$.

O modelo tradicional de assistência à família, centrado na figura materna, deve ser repensado para a inserção do pai, buscando humanizar o atendimento, visto que já é possível observar uma nova realidade cultural, na qual os homens cuidam do lar e dos filhos junto com as mulheres e elas, por sua vez, trabalham fora, junto aos homens ${ }^{13}$.

Soma-se a isso a influência positiva que a presença paterna pode gerar na saúde da mulher, tendo em vista que o parceiro costuma ser a única ou a principal referência emocional e social da gestante, principalmente quando a família é formada apenas pelo casal. Nesse sentido, a participação do homem em atividades educativas e consultas prénatais são fundamentais para o exercício da paternidade ainda no período gestacional, 
além de proporcionar informações que garantam segurança e credibilidade no apoio à mulher durante esse período ${ }^{5}$.

No entanto, mesmo sendo explícita a necessidade de aproximação do homem aos serviços de saúde, com vistas a uma melhoria no atendimento e acolhimento a esse público no período gestatório, observa-se, por meio da literatura, que o homem ainda é excluído dessa assistência, o que sugere pensar que o período gestacional ainda é percebido, por muitos, como assunto único e exclusivo de mulheres ${ }^{2,10}$.

Desse modo, nota-se o quão fundamental é o estímulo advindo do profissional de saúde do pré-natal, parto, nascimento e puerpério para que haja uma boa interação do trinômio pai-mãe-filho. Além do mais, a garantia da presença do pai nas consultas e, porventura, nos exames de ultrassonografia, surge como uma forma de promover o início do vínculo pai-bebê e, tudo isso, culmina na humanização do parto e nascimento ${ }^{13}$.

A presença do pai no parto, por exemplo, acompanhado pela equipe de saúde, sendo bem orientado e acolhido, pode favorecer o relacionamento futuro com seu filho. Porém, para que a presença do pai durante o parto seja positiva, ele necessita de treinamento e apoio ${ }^{10,13}$.

Sobre isso, alguns autores ainda pontuam que, apesar de muitos profissionais e futuros pais acreditarem na importância da participação do pai no parto, deve-se relembrar que, para alguns pais, a vivência deste importante momento pode ser traumática ou mesmo insuportável ${ }^{10}$.

Contudo, o parto é um momento cheio de significações para o homem, sendo que sua presença, no momento, melhora a interação com a companheira, podendo refletir no relacionamento futuro com o filho, permitindo uma transição para a parentalidade de maneira mais facilitada ${ }^{13}$.

Por tudo isso, argumenta-se a necessidade do fortalecimento de políticas de garantia de direitos sociais e de saúde que facilitem e encorajem o engajamento do homem/pai em todos os aspectos que envolvem o período gestacional ${ }^{14}$.

\section{CONCLUSÃO}

Ante ao exposto, é possível concluir que o envolvimento paterno durante o período gravídico-puerperal se dá principalmente no final da gestação e a partir do nascimento da criança, haja vista a dificuldade de formulação ideológica da criança que o homem possui, somado pela incompreensão completa desse momento vivido mais intensamente pela mulher. 
Em conclusão, o presente estudo demonstra o quão complexo é conformação paterna no ciclo gestatório e sua tendência natural de distanciar-se do processo, contribuindo consequentemente para fragilização dos vínculos formados entre pai e filho e para dificuldade do desenvolvimento de práticas de cuidado.

Portanto, é preciso fortalecer a participação paterna durantes as consultas de prénatal através de estratégias de incentivo, buscando descontruir o afastamento paterno desse momento e provendo informações que facilitem o cuidado fornecido ao binômio mãe-filho nesse período.

Como limitação do estudo, está ao fato das pesquisas feitas serem somente no idioma português, excluindo assim outros, mas que apesar disso, o trabalho representa uma visão histórico-cultural dá a participação do homem/pai brasileiro durante o período gravídico puerperal.

Assim sendo, quanto aos profissionais de saúde, é necessário que haja a necessidade de reconhecimento da importância do indivíduo, bem como que este seja incentivado a participar desses períodos demonstrando a relevância para sie para os demais envolvidos. Além disso, pode-se criar estratégias como a busca ativa desde o planejamento familiar, assim como, por meio artifícios educacionais, como a educação popular em saúde para inserção e participação ativa do parceiro em todo o ciclo gravídico-puerperal.

\section{REFERÊNCIAS}

1. Santos CVM, Antunez AE. Paternidade afetivamente inscrita: modalidades de interação na relação paibebê. Arq. bras. Psicol. [Internet] 2018 [citado em 2020 Jul 25];70(1):224-38. Disponível em: http://pepsic. bvsalud.org/pdf/arbp/v70n1/16.pdf.

2. Sonego JC, Dornelles LMN, Lopes RCS, Piccinini CA, Passos EP. A Experiência Paterna da Gestação no Contexto da Reprodução Assistida. Psic.: Teor. e Pesq. [Internet]. 2016 [citado em 2020 Jul 25];32(4):e324218. Disponível em: https://www.scielo.br/pdf/ptp/v32n4/1806-3446-ptp-32-04-e324218.pdf.

3. Bencke MP, Kruel CS. A experiência do homem, ao tornar-se pai, no contexto gestacional e nos primeiros meses de vida do bebê. Psicol. rev. [Internet]. 2018 [citado em 2020 Jul 25];24(2):402-23. Disponível em: http://dx.doi.org/10.5752/P.1678-9563.2018v24n2p402-423.

4. Trindade Z, Cortez MB, Dornelas K, Santos M. First-time fathers: demand for support and visibility. Saude soc. [Internet] 2019 [citado em 2020 Jul 24];28(1):250-61. Disponível em: https://doi.org/10.1590/ s0104-12902019170892.

5. Cavalcanti TRL, Holanda VR. Participação paterna no ciclo Gravídico-puerperal e seus efeitos sobre a saúde da mulher. Enferm. Foco [Internet]. 2019 [citado em 2020 Jul 24];10(1):93-8. Disponível em: http:// revista.cofen.gov.br/index.php/enfermagem/article/view/1446/502.

6. Whittemore R, Knafl K. The integrative review: updated methodology. J Adv Nurs. [Internet]. 2005 [citado em 2020 Jul 12];52(5):546-53. Disponível em: https://doi.org/10.1111/j.1365-2648.2005.03621.x.

7. Moher D, Liberati A, Tetzlaff J, Altman DG. The PRISMA Group 2009. Preferred reporting items for systematic reviews and meta-analyses: the PRISMA Statement. PLoS Med. [Internet]. 2009 [citado em 2020 Jul 12];6(6):e1000097. Disponível em: https://doi.org/10.1371/journal.pmed.1000097 
8. Freitas WMF, Coelho EAC, Silva ATMC. Sentir-se pai: a vivência masculina sob o olhar de gênero. Cad. Saúde Pública [Internet]. 2007 [citado em 2020 Jul 25];23(1):137-45. Disponível em: https://doi. org/10.1590/S0102-311X2007000100015.

9. Krob AD, Piccinini CA, Silva MR. A transição para a paternidade: Da gestação ao segundo mês de vida do bebê. Psicol. USP [Internet]. 2009 [citado em 2020 Jul 25];20(2):269-91. Disponível em: http://pepsic. bvsalud.org/pdf/psicousp/v20n2/v20n2a08.pdf.

10. Piccinini CA, Silva MR, Gonçalves TR, Lopes RS, Tudge J. O envolvimento paterno durante a gestação. Psicol. Reflex. Crit. [Internet] 2004 [citado em 2020 Jul 25];17(3):303-14. Disponível em: http://dx.doi. org/10.1590/S0102-79722004000300003.

11. Piccinini CA, Levandowski DC, Gomes AG, Lindenmeyer D, Lopes RS. Expectativas e sentimentos de pais em relação ao bebê durante a gestação. Estud. psicol. (Campinas) [Internet]. 2009 [citado em 2020 Jul 25];26(3):373-82. Disponível em: http://dx.doi.org/10.1590/S0103-166X2009000300010.

12. Matos MG, Magalhães AS, Féres-Carneiro T, Machado RN. Construindo o Vínculo Pai-Bebê: Uma Experiência dos Pais. Psico-USF [Internet]. 2017 [citado em 2020 Jul 25];22(2):261-71. Disponível em: https://doi.org/10.1590/1413-82712017220206.

13. Soares RLSF, Christoffel MM, Rodrigues EC, Machado MED, Cunha AL. Being a father of a premature newborn at neonatal intensive care unit: from parenthood to fatherhood. Esc. Anna Nery [Internet]. 2015 [citado em 2020 Jul 25];19(3):409-16. Disponível em: http://dx.doi.org/10.5935/1414-8145.20150054.

14. Castoldi L, Gonçalves TR, Lopes RCS. Envolvimento paterno da gestação ao primeiro ano de vida do bebê. Psicol. Estud. [Internet]. 2014 [citado em 2020 Jul 25];19(2):247-59. Disponível em: https://doi. org/10.1590/1413-737222105008.

RECEBIDO: 01/08/2020

ACEITO: 07/10/2020 